\title{
Zentralvorstandssitzung vom 19. April 2012
}

Ärztliche Medikamentenabgabe - Ab 1. Mai 2012 können auch in Winterthur und Zürich ambulant tätige Ärztinnen und Ärzte Medikamente abgeben. Entgegen der gemeinsamen Absichtserklärung zwischen FMH und santésuisse erwartet tarifsuisse immer noch eine Senkung der betriebswirtschaftlichen Marge mit einem Einsparpotential von über 200 Millionen Franken. Die FMH wird deshalb das Gespräch mit dem Verwaltungsrat der santésuisse suchen. Der Bundesrat erwartet ein margenfreies Abgeltungsmodell.

2. DRG-Forum Schweiz-Deutschland - Die FMH soll wie in diesem Jahr auch 2013 das 2. DRG-Forum Schweiz-Deutschland mit einem Patronat sowie finanziell unterstützen. Die bei diesem Forum entstehenden Kontakte und Projekte sollen zusammengetragen werden. So wird die Investition messbar, und für die nächsten Anfragen wird eine gute Entscheidungsgrundlage vorliegen.

Tagung Qualitätsmedizin - Diese Tagung vom 14. September 2012 spricht ein etwas anderes Zielpublikum an als üblich; es geht vor allem um Qualität, Tarifstrukturen und verwandte Themen. Der Zentralvorstand (ZV) stimmt deshalb dem Patronat zu und wird die Referentin/den Referenten für den Anlass im Juni bestimmen.

Impftag für Parlamentarier - Die Parlamentsmitglieder sollen ihr Umfeld für die Grippeimpfung motivieren, um gegen die sinkende Impfwilligkeit ein Zeichen zu setzen. Die FMH begrüsst die Tatsache, dass geimpft wird, und möchte die Grundversorger am Impftag einbeziehen. Sie übernimmt das Patronat des Impftages und stellt ihr Logo dafür zur Verfügung.

Allfälliges Referendum gegen die IV-Revision $6 \mathrm{~b}-$ Die «Coordination Romande pour la Santé Psychique» hat die FMH angefragt, ob sie einem allfälligen Referendumskomitee gegen die IV-Revision $6 \mathrm{~b}$ beitreten würde. Die Revision 6b ist Teil eines Reformpaketes, dessen Zielsetzung die finanzielle Sanierung dieser stark verschuldeten sozialen Versicherung ist. Die Vorlage ist aus der Sicht der Behindertenorganisationen eine reine Sparvorlage, die diese so nicht hinnehmen wollen. Der ZV entscheidet, dass es für das Ergreifen des Referendums zu früh sei und dass es eine vertiefte Diskussion des ganzen Themas an der nächsten Delegiertenversammlung braucht.

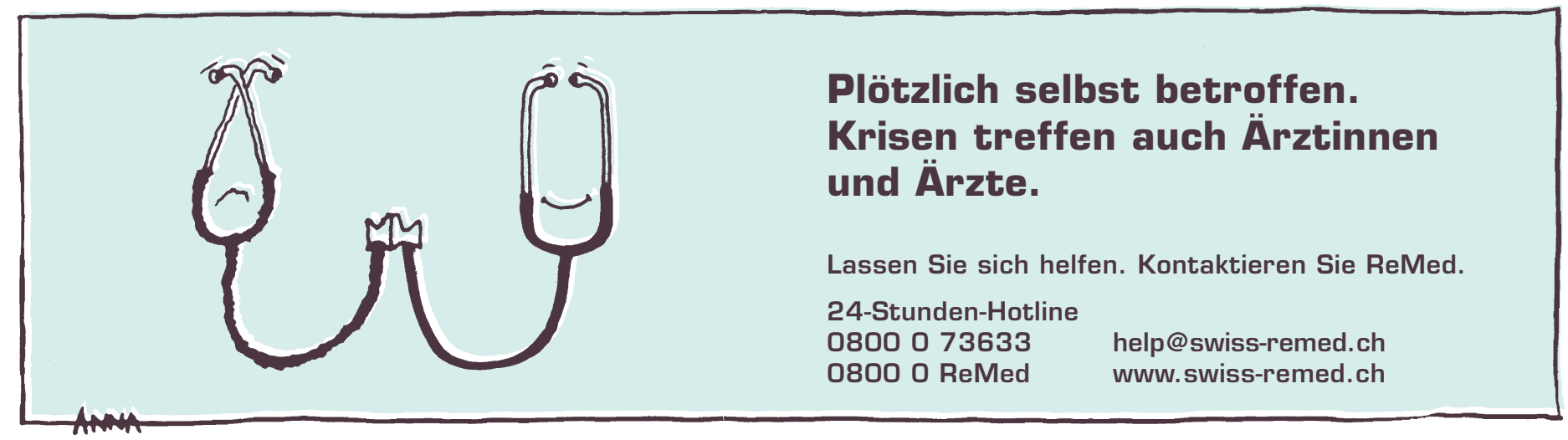

